\title{
The Effect of Diagnosis of Covid-19 on Sleep Quality in Emergency Service Personnel: A Comparative Study
}

\author{
Serdar Derya ${ }^{1(\mathrm{ID})}$, Bora Tetik ${ }^{2(\mathrm{ID})}$ \\ ${ }^{1}$ Department of Traumatology and Emergency Medicine, Malatya Training and Research Hospital, Malatya / Turkey \\ ${ }^{2}$ Deparment of Neurosurgery, Inonu University School of Medicine, Malatya / Turkey.
}

Copyright@ Author(s) - Available online at https://dergipark.org.tr/en/pub/mbsjohs

Content of this journal is licensed under a Creative Commons Attribution-NonCommercial 4.0 International

License,

Received: 17 July 2020, Accepted: 16 October 2021, Published online: 31 December 2021

(C) Ordu University Institute of Health Sciences, Turkey, 2021

\begin{abstract}
Objective: The COVID-19 pandemic, is an important health problem that affects our lives in social, political, economic and psychological areas In this study, it was aimed to determine the effect of diagnosis of COVID19 on sleep quality in emergency service personnel.

Methods: In this comparative study, 66 personnel providing emergency services and diagnosed with COVID-19 were compared with 66 personnel providing emergency services who were not diagnosed with COVID-19. The data were obtained through the Personal Information Form and Pittsburgh Sleep Quality Index (PSQI).

Results: The average time after diagnosis in personnel diagnosed with COVID-19 ( $\mathrm{n}=66$ ) was 5.52 \pm 2.27 months. It was determined that the mean total score of PSQI was $18.03 \pm 1.73$ in emergency service personnel diagnosed with COVID-19 and 16.71 \pm 2.28 in emergency service personnel who were not diagnosed with COVID-19, and the difference between the groups was statistically significant $(p=0.000)$. As the time passed after the diagnosis of COVID-19, it was determined that the mean total score of PSQI decreased statistically significantly, that is, the quality of sleep increased $(\mathrm{p}=0.027)$.

Conclusion: It was observed that the sleep quality of the emergency service personnel diagnosed with COVID-19 was worse compared to the personnel who were not diagnosed, however, the sleep quality increased significantly as the time passed after the diagnosis.

Key words: Emergency service personnel, COVID-19 diagnosis status, sleep quality.
\end{abstract}

Suggested Citation: Derya S, Tetik B. The Effect of Diagnosis of Covid-19 on Sleep Quality in Emergency Service Personnel: A Comparative Study. Mid Blac Sea Journal of Health Sci, 2021; 7(3):334-339.

Address for correspondence/reprints:

Bora Tetik

Telephone number: +90-(422) 34106 60-3207

E-mail: drboratetik@ hotmail.com 


\section{Introduction}

The COVID-19 pandemic, which started in China and affected the whole world, is an important health problem that affects our lives in social, political, economic and psychological areas (1). Although there is not enough evidence yet, there is increasing evidence in the scientific literature that COVID-19 disease is increasingly associated with mental and neurological symptoms, including delirium, anxiety, sleep disorders, and depression $(2,3)$. It is stated that factors such as precautions, compulsory changes related to work and education, and economic difficulties play a role in this increase in psychological health problems, as well as the effect of quarantine and treatment processes and unavoidable death rates $(4,5)$.

The fact that the cause of the emergence of COVID-19 is not known exactly, the virus cannot be controlled and all individuals in the world are at potential risk have turned the epidemic into a global trauma (1). As the prevalence and death rate of infectious diseases increase, it is inevitable that individuals' fear, depression and anxiety levels will increase (6). There are cross-sectional studies emphasizing that the prevalence of stress-related psychiatric symptoms in the general population causes an increase in depression, anxiety, and sleep problems $(5,7)$.

The COVID-19 epidemic has affected the social and business environments in various ways (2). COVID-19 has psychological effects on health workers, as in many occupational groups, and it is emphasized in the literature that especially frontline workers are at risk $(5,8,9)$. Healthcare professionals dealing with the diagnosis, treatment and care of patients diagnosed with COVID-19 may show symptoms of stress, depression and insomnia more frequently (1). In this process, negative emotions such as worry, depression and anxiety may impair the sleep quality of individuals $(6,10)$. Sleep is a vital process for quality of human life and maintaining homeostasis.

Good sleep quality has effects on physical and mental health (11). For this reason, it is important that health workers who provide treatment and care for individuals diagnosed with COVID-19 have good sleep quality (6). In the literature, it is stated that the physical and psychological health levels of health personnel are at risk due to their working conditions, and that the anxiety and stress experienced may negatively affect sleep (12). The possibility that problems such as posttraumatic stress disorder, depression, anxiety and sleep disorders affect healthcare professionals, especially those who are in contact with the public at the front, increases the importance given to the issue (2). It can be thought that the impact on emergency service personnel who are in contact with the public, especially on the front, will be inevitable and higher. Based on this information, it was aimed to determine the effect of diagnosis of COVID-19 on sleep quality in emergency service personnel. The secondary aim is to compare the demographic characteristics and sleep quality of 112 personnel diagnosed with covid-19.

\section{Methods}

This study was designed as a comparative study to determine the effect of diagnosis of COVID-19 on sleep quality in emergency service personnel. The universe of the research consisted of all Emergency Medical Technicians (EMT), Paramedics and Doctors serving under the Provincial Ambulance Service Chief Physician in a province in the east of Turkey. The number of personnel diagnosed with COVID-19 during the pandemic process is approximately 130 . The research was carried out in April 2021 and 66 emergency service personnel diagnosed with COVID-19 were compared with 66 emergency service personnel not diagnosed with COVID-19. Personnel without any diagnosed sleeping disorder were included in the study. Emergency service personnel included in the study were selected from the relevant population by simple random sampling method.

\section{Data Collection Tools}

Personal Introduction Form and Pittsburgh Sleep Quality Index are used to obtain the data.

\section{Personal Introduction Form}

This 8-question form prepared by the researchers consists of questions questioning the introductory characteristics (age, gender, education level, income status, etc.) of the 112 emergency service personnel included in the study and their diagnosis during the COVID-19 pandemic process. 
Pittsburg Sleep Quality Index (PSQI)

Pittsburgh sleep quality index (PSQI) is a measuring tool that provides knowledge about sleep quality and the type and severity of sleep disorder in the last month, and is used to determine sleep quality. It was developed by Buysse and his friends in 1989 (13). 19 of 24 questions in the scale, which was adapted into Turkish by Ağargün and his friends, are self-report questions. The total PSQI score ranges from 0-21. High scores define poor sleep quality and high level of sleep disturbance. The Cronbach's alpha coefficient of the Pittsburgh Sleep Quality Scale was found to be 0.80 (14). In this study, the Cronbach's alpha coefficient of the Pittsburgh Sleep Quality Scale was found to be 0.69 .

\section{Data Collection}

The data collection phase of this research was carried out using the Google Form method (Google Forms $\left.{ }^{\circledR}\right)$. Emergency service personnel were reached via the Internet on WhatsApp and data collection forms were sent to the participants using the Google Form method. Emergency service personnel who agreed to participate in the study were first asked to approve the informed consent form, and the personnel who gave consent were directed to the data collection forms via the internet. All data obtained by the online self-report method was recorded with the Google Form method.

\section{Statistical analysis}

The data were evaluated using the SPSS 24.0 statistical package program. In the evaluation of the data, descriptive statistics (min-max values, mean, standard deviation, number and percentage) as well as one-way anova test, independent groups t test and Pearson correlation analysis were used. The results were evaluated at the $95 \%$ confidence interval and the significance was evaluated at the $\mathrm{p}<0.05$ level.

\section{Results}

In Table 1, the distribution of the descriptive characteristics of the emergency service personnel is given. 53\% of the personnel diagnosed with covid-19 are male, $43.9 \%$ have a associate degree, $45.5 \%$ are EMT, and the rate of those who state that their income is equal to their expenses is $56.1 \%$. $63.6 \%$ of the personnel who are not diagnosed with covid-19 are women, $47 \%$ have a associate degree, $48.4 \%$ are EMT, and the rate of those who state that their income is less than their expenses is $54.5 \%$ (Table 1).

In Table 2, the comparison of the sleep quality of the emergency service personnel with and without the diagnosis of COVID-19 is given. It was determined that the mean total score of PSQI was $18.03 \pm 1.73$ in emergency service personnel diagnosed with COVID-19, and $16.71 \pm 2.28$ in emergency service personnel who were not diagnosed, and the difference between the groups was statistically significant $(\mathrm{p}<0.001)$. High values obtained from PSQI indicate poor sleep quality and high level of sleep disturbance (Table 2).

In Table 3, it was seen that the time passed after the diagnosis of COVID-19 in the emergency service personnel diagnosed with COVID-19, the time passed after the diagnosis of COVID-19, and the total score of PSQI increased as the time passed after the diagnosis of COVID-19, the average of the total score of PSQI decreased, that is, the quality of sleep increased (Table 3). In addition, no relationship was found between age and working year and sleep quality.

Table 4 shows comparison of descriptive characteristics and sleep quality in emergency service personnel diagnosed with COVID-19. No difference was found between gender, education level, profession and perceived income status and sleep quality of the personnel who had diagnosed with COVID-19 ( $p>0.05)$. 
$\underline{\text { Table 1. Distribution of descriptive characteristicsof emergency service personnel }(n=132)}$

\begin{tabular}{|c|c|c|}
\hline Variables & $\begin{array}{c}\text { Diagnosed With COVID- } \\
19(n=66) \\
n(\%) \\
\end{array}$ & $\begin{array}{c}\text { Not Diagnosed With COVID-19 } \\
(\mathbf{n}=66) \\
\mathrm{n}(\%)\end{array}$ \\
\hline \multicolumn{3}{|l|}{ Gender } \\
\hline Female & $31(47.0)$ & $42(63.6)$ \\
\hline Male & $35(53.0)$ & $24(36.4)$ \\
\hline \multicolumn{3}{|l|}{ Education } \\
\hline High school & $8(12.2)$ & $19(28.8)$ \\
\hline Associate degree & $29(43.9)$ & $31(47.0)$ \\
\hline Bachelor degree & $29(43.9)$ & $16(24.2)$ \\
\hline \multicolumn{3}{|l|}{ Profession } \\
\hline Paramedic & $28(42.4)$ & $30(45.5)$ \\
\hline EMT & $30(45.5)$ & $32(48.4)$ \\
\hline Doctor & $8(12.1)$ & $4(6.1)$ \\
\hline \multicolumn{3}{|l|}{ Perceived income status } \\
\hline My income less my expense & $23(34.8)$ & $36(54.5)$ \\
\hline My income equivalent to my expense & $37(56.1)$ & $27(41.0)$ \\
\hline \multirow[t]{2}{*}{ My income more than my expense } & $6(9.1)$ & $3(4.5)$ \\
\hline & Mean \pm SD & Mean \pm SD \\
\hline Age (year) & $29.22 \pm 5.74$ & $31.39 \pm 9.13$ \\
\hline Working year & $7.86 \pm 4.01$ & $8.69 \pm 7.24$ \\
\hline Time/Month after COVID-19 diagnosis & $5.52 \pm 2.27$ & - \\
\hline
\end{tabular}

Table 2. Comparison of sleep quality of emergency service personnel with and without COVID-19 diagnosis ( $\mathrm{n}=132$ )

\begin{tabular}{|c|c|c|}
\hline COVID-19 Diagnosis Status & $\begin{array}{c}\text { PSQI } \\
\text { Mean } \pm \text { SD }\end{array}$ & Test and $p$ value \\
\hline Yes $(n=66)$ & $18.03 \pm 1.73$ & $t=3.731$ \\
\hline No $(n=66)$ & $16.71 \pm 2.28$ & $\mathrm{p}=0.000$ \\
\hline
\end{tabular}

Table 3. The relationship between the time passed after COVID-19 diagnosis, age and working year and sleep quality in emergency service personnel diagnosed with COVID-19 $(n=66)$

\begin{tabular}{lc}
\hline Variables & PSQI \\
\hline Age/ Year & $\mathrm{r}=0.058$ \\
& $\mathrm{p}=0.644$ \\
\hline Working year & $\mathrm{r}=0.054$ \\
& $\mathrm{p}=0.669$ \\
\hline Time/Month after COVID-19 diagnosis & $\mathrm{r}=-0.275$ \\
& $\mathrm{p}=\mathbf{0 . 0 2 7 ^ { * }}$ \\
\hline
\end{tabular}

${ }^{*} \mathrm{p}<0.05 \quad \mathrm{r}=$ Pearson correlation analysis

Table 4. Comparison of descriptive characteristics and sleep quality in emergency service personnel diagnosed with COVID-19 $(\mathrm{n}=66)$

\begin{tabular}{|c|c|c|c|}
\hline Variables & $\mathbf{n}$ & $\begin{array}{c}\text { PSQI } \\
(\mathrm{Mean} \pm \mathrm{SD}) \\
\end{array}$ & Test and $p$ value \\
\hline \multicolumn{4}{|l|}{ Gender } \\
\hline Female & 31 & $18.00 \pm 1.93$ & $\mathrm{t}=-0.312$ \\
\hline Male & 35 & $18.05 \pm 1.57$ & $\mathrm{p}=0.895$ \\
\hline \multicolumn{4}{|l|}{ Education } \\
\hline High school & 8 & $18.12 \pm 1.88$ & $\mathrm{~F}=0.150$ \\
\hline Associate degree & 29 & $17.89 \pm 1.54$ & $\mathrm{p}=0.861$ \\
\hline Bachelor degree & 29 & $18.13 \pm 1.92$ & \\
\hline \multicolumn{4}{|l|}{ Profession } \\
\hline Paramedic & 28 & $17.64 \pm 1.68$ & $\mathrm{~F}=2.063$ \\
\hline EMT & 30 & $18.13 \pm 1.61$ & $\mathrm{p}=0.136$ \\
\hline Doctor & 8 & $19.00 \pm 1.13$ & \\
\hline \multicolumn{4}{|l|}{ Perceived income status } \\
\hline My income less my expense ${ }^{a}$ & 23 & $18.73 \pm 1.91$ & $\mathrm{~F}=0.501$ \\
\hline My income equivalent to my expense ${ }^{b}$ & 37 & $17.48 \pm 1.42$ & $\mathrm{p}=0.608$ \\
\hline My income more than my expense ${ }^{c}$ & 6 & $18.66 \pm 1.86$ & \\
\hline
\end{tabular}

EMT: Emergency Medical Technician, $\mathrm{t}=$ Independent groups $\mathrm{t}$ test, $\mathrm{F}=\mathrm{One}$-way anova test, Mean $\pm \mathrm{SD}=\mathrm{Mean}$ and standard deviation 


\section{Discussion}

Individuals with COVID-19 have to cope with many sources of stress, such as uncertainty about the process, fear of infecting their relatives, and exclusion from society, as well as the physical effect of the disease. Health workers, especially those who have the closest contact with infected people, carry a high risk of transmission while fighting the epidemic. Especially the mental health of the health personnel working in intensive care units, 112 emergency service command center and emergency services is severely affected and this causes psychiatric problems such as sleep disorders, depression and anxiety. In the literature, it has been reported that psychological effects are higher in high-risk groups, primarily healthcare workers (4).

Sleep; It is the time period when the immune system continues to work, the nervous system rests, individuals are freed from complex thoughts and go to rest (6). In the current pandemic period, it is obvious that the working conditions of healthcare workers have become more difficult, their shifts have increased and their sleep patterns have been disturbed (3). Although there is not enough evidence yet, there is evidence in the literature that COVID-19 disease is increasingly associated with mental and neurological symptoms, including delirium, anxiety, sleep disorders, and depression. Studies conducted in the last ten years have gradually increased the view that sleep disorders have a strong effect on the risk of infectious diseases, the occurrence and progression of a number of diseases, and the incidence of depression (11). In Liu and his friends' study during the pandemic period, the rate of those who thought their sleep patterns were very good and good was $80 \%$, and the rate of those who slept more than 7 hours was $53 \%$ (15). In the study conducted by Cansel et al. across Turkey, it was found that $53 \%$ of the participants slept for more than 8 hours, there was no disturbance in their sleep quality, and their anxiety levels were lower (16). In our study, it was found that those diagnosed with COVID-19 from the PSQI, the scale by which we evaluate sleep quality, received higher scores and had worse sleep quality. Sleep quality is an important indicator of health. Good sleep quality for clinical staff not only enables them to work more effectively to treat patients, but also maintains optimal immune function to prevent infection. Therefore, sleep quality is an important indicator for health (12). In addition, in our study, it was observed that as the time passed after being diagnosed with COVID-19 increased, the PSQI score decreased and sleep quality increased. Therefore, in order to improve the sleep quality of healthcare personnel with COVID-19, a comprehensive approach should be provided.

The authors found that anxiety was associated with stress and poor sleep quality, and that the combination of anxiety and stress reduced sleep quality. In a study conducted during the pandemic process, it was reported that $50.4 \%$ of healthcare professionals experienced depression, $44.6 \%$ had anxiety and $34.0 \%$ had insomnia (10). In a study conducted by Xiao et al. on healthcare professionals in China who were involved in the treatment of patients with COVID-19 infection; determined that anxiety level is a related factor that negatively affects sleep quality (12). In addition, in the literature, it is stated that the COVID-19 pandemic may increase sleep disorders and damage the function of the immune system (11). Work-related stress, sleep deprivation, shift work and fatigue often cause sleep disturbances and poor sleep quality in healthcare workers (17). Based on these data, it is necessary to improve the working conditions of health workers in order to provide sleep quality during the pandemic period.

\section{Conclusion}

It was observed that the sleep quality of the emergency service personnel who were diagnosed with COVID-19 was worse compared to the personnel who were not diagnosed, but the sleep quality increased significantly as the time passed after the diagnosis increased. In line with these results; It can be said that there is a need for action plans to reduce the effects of COVID-19 on mental health in order to protect sleep quality and psychological health of healthcare workers during and after the epidemic. Of course, although psychological impact is an expected result in an extraordinary situation like a pandemic, the continuation of the danger and restrictions will cause permanent psychological and biological effects. Therefore, while evaluating the pandemic in healthcare professionals, it will be important to determine the psychological problems and related factors that may develop afterwards, to determine the target group and to take the necessary precautions, and to direct the aid.

\section{Limitation}

This study has some limitations; firstly, sleep quality don't relate only to infectious disease. Other factors haven't been investigated for this study. In addition, the other limitation of the study is that the 
data were obtained from emergency service personnel working in only one province.

\section{Acknowledgements}

We would like to thank the emergency service personnel who participated in and completed this questionnaire.

Ethics Committee Approval: The Ministry of Health of the Republic of Turkey Covid-19 Scientific Research permission was obtained (Form number: 2021-03-27T19_11_16). In addition, following the permission of the Ministry of Health, ethical approval (2021/1912) was obtained from the Local Ethic Committee.

Peer-review: Externally peer-reviewed.

\section{Author Contributions:}

Concept: S.D, Design: S.D, B.T; Literature search: S.D, B.T, Data Collection and Processing: S.D, B.T, Analysis or Interpretation: S.D, B.T, Writing: S.D, B.T.

Conflict of Interest: No conflict of interest was declared by the authors.

Financial Disclosure: The financial support for this study was provided by the investigators themselves.

\section{References}

1. Askin R, Bozkurt Y, Zeybek Z. Covid-19 pandemic: psychological effects and therapeutic interventions. Istanbul Commerce University Journal of Social Sciences Covid-19 Social Sciences Special Issue 2020; 19(37): 304-18

2. Giorgi G, Lecca LI, Alessio F, Libera Finstad G, Bondanini G, Ginecra Lulli L. et al. COVID-19related mental health effects in the workplace: a narrative review. International Journal of Environmental Research and Public Health 2020;17(21):7857.

3. Cosar B (editor) Psychiatry and COVID-19: Baltacı NN, Coşar B. Covid-19 pandemic and the mind body dualism. 1st edition, Ankara: Turkey Clinics 2020:1-6.

4. Moreno C, Wykes T, Galderisi S et al. How mental health care should change as a consequence of the COVID-19 pandemic. Lancet Psychiatry 2020; 7(9): 813-24.

5. Basar K. Psychiatry during and after the Covid-19 epidemic: the role of the Turkish Psychiatric Association. Turkish Journal of Psychiatry 2020; 31(3):1-3.
6. Sayik D, Acikgoz A, Mutlu F. Sleep Quality of Healthcare Personnel in the Coronavirus Pandemic: Meta-analysis. Journal of Turkish Sleep Medicine 2021;1:1-6.

7. Vindegaard N, Benros ME. COVID-19 pandemic and mental health consequences: Systematic review of the current evidence. Brain Behav Immun 2020;89:531-42.

8. Blake H, Bermingham F, Johnson G, Tabner A. Mitigating the psychological impact of COVID19 on healthcare workers: a digital learning package. International journal of environmental research and public health 2020; 17(9):2997

9. Moreno C, Wykes T, Galderisi S, Nordentof M, Crossley N, Jones N. et al. How mental health care should change as a consequence of the COVID-19 pandemic Lancet Psychiatry 2020; 7: 813-24.

10. Sher L. COVID-19, anxiety, sleep disturbances and suicide. Sleep medicine 2020; 70:124

11.Silva ESM, Ona BHVS, Souza, JC. Sleep and immunity in times of COVID-19. Revista da Associação Médica Brasileira 2020;66:143-7.

12.Xiao H, Zhang Y, Kong D, Li S, Yang N. The effects of social support on sleep quality of medical staff treating patients with coronavirus disease 2019 (COVID-19) in January and February 2020 in China. Medical science monitor: international medical journal of experimental and clinical research 2020; 26, e923549-1.

13. Buysse DJ, Reynolds III CF, Monk TH, Berman SR, \& Kupfer DJ. The Pittsburgh Sleep Quality Index: a new instrument for psychiatric practice and research. Psychiatry research 1989;28(2):193213.

14.Ağargün MY, Kara H, Anlar O. Validity and Reliability of the Pittsburgh Sleep Quality Index. Turkish Journal of Psychiatry 1996;7:107-11.

15.Nianqi Liu, Fan Zhang, Cun Wei, Yanpu Jia, Zhilei Shang, Luna Sun, et al. Prevalence and predictors of PTSS during COVID-19 outbreak in China hardest-hit areas: Gender differences matter Psychiatry Res. 2020 May; 287: 112921.

16. Cansel N, Ucuz I, Arslan AK, Kayhan Tetik B, Colak C, Melez SNI et al. Prevalence and predictors of psychological response during immediate COVID-19 pandemic. Int J Clin Pract. Int J Clin Pract. 2021;75:1-14.

17.Akinci T, Basar HM. Assessment of Sleep Quality in Healthcare Workers as Part of the COVID-19 Outbreak. Turkish Journal of Neurology/Turk Noroloji Dergisi 2021; 27(2):176-186. 